\title{
The effect of building materials choice on the thermal comfort in the self-produced individual housing in Biskra.
}

\author{
Latreche $S^{*}$, Sriti L \\ Department of Architecture , University of Biskra, BP 145 RP, 07000 Biskra, Algeria \\ * Corresponding Author: sihem.latreche21@gmail.com
}

\begin{abstract}
The building envelope is the first barrier to protect against external climatic variations. Generally, it consists of two types of walls: opaque walls (walls and roof) and transparent walls (Windows). The design characteristics of the enclosure strongly affect the occupants' thermal comfort, as well as the building energy consumption. The constructive choices relating to structural elements, in particular, walls, roofing and openings are generally considered in the thermal exchanges between the building and its environment. In the present study, which is based on experimental analysis in the self-generated residential sector in Biskra (Algeria), where a warm and arid climate predominates, we aim to evaluate the thermal impact of certain architectural and constructive parameters that are specific to residential habitat self-produced in Biskra. This paper summarizes the main results obtained from an in situ measurement campaign that evaluated the essential parameters of thermal comfort such as ambient and surface temperature, air velocity, and humidity. These parameters were used as indicators to measure the impact of the envelope material characteristics on its climatic adaptability. This paper also presents some recommendations for optimizing the choice of building materials specific to the self-produced residential in order to improve its thermal performance while preserving the essentials of its specificities.
\end{abstract}

Key words: Construction materials, thermal comfort, Individual housing self-produced, hot and arid climate, Biskra.

\section{Introduction}

In Algeria, there are several reasons for the evolution of the constructive system in the individual housing, in particular the appearance of new materials and construction techniques as well as new modes of architectural design. Unfortunately, this revolution in architectural practice has ignored the specificities of the climate context, which has led to a rupture between the framework and its environment and an abusive and irrational exploitation of the resources Energy. Thus, electricity consumption in the residential sector in Algeria represents $28 \%$ of the total consumption of electricity (APRUE, 2015). This consumption is essentially, intended to cover the needs of artificial lighting, heating and air conditioning (Figure. 1); it is experiencing a growing trend in particular for the residential sector (Figure.2).

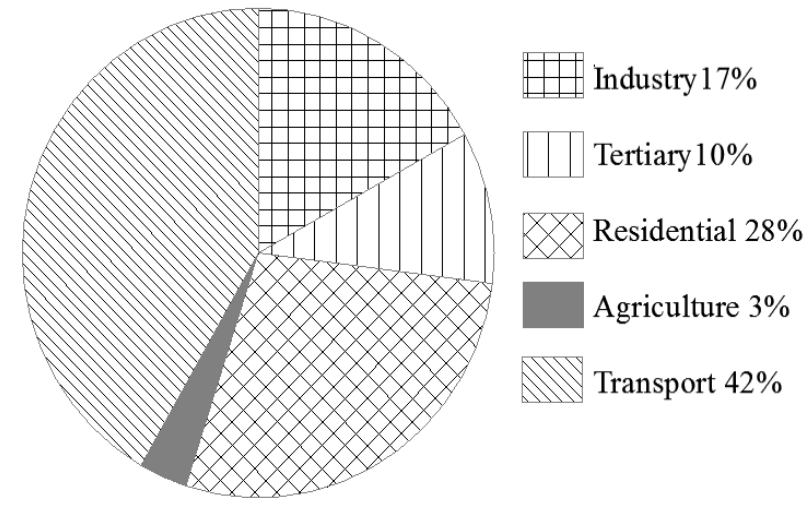

Fig. 1. Distribution of energy consumption by sector in Algeria (Source: APRUE, 2015).

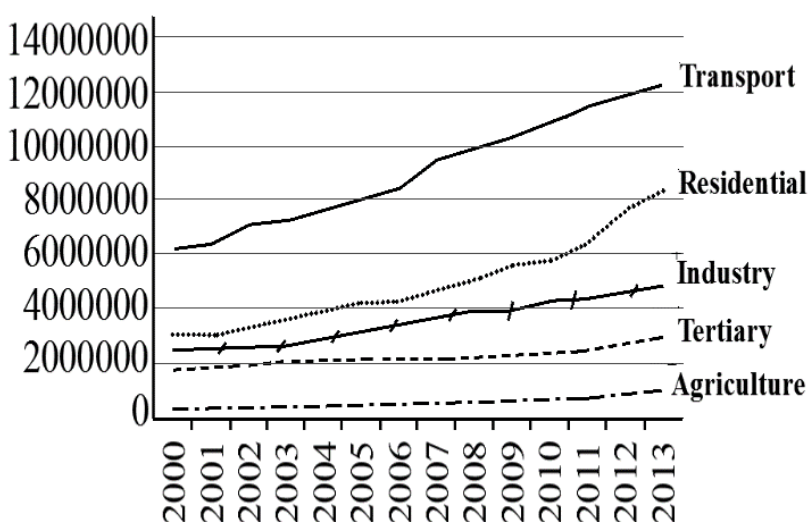

Fig. 2. Evolution of energy consumption by sector in tep (Source: APRUE, 2015). 
The city of Biskra, which is characterized by a hot and arid climate, illustrates the magnitude of this phenomenon. Since a few decades, the built frame produced in this city has no relation with the climatic conditions, which drives the inhabitants to turn to the mechanical means to ensure a certain level of comfort whose cost is each year more High. In addition, it is to reduce this energy consumption and ensure optimum climatic comfort that must be taken on architectural design.

As such, the design characteristics of the envelope strongly affect the thermal comfort of the occupants, as well as the energy consumption in the building. The climate and energy performance of the envelope depends on the constructive choices relating to the structural elements, in particular the walls, the roof and the openings generally considered as determining factors in trade between the building and its environment.

The objective of this study is to evaluate the thermal impact of the structural and constructive elements of the envelope as they are used in the residential housing produced in Biskra. The ultimate goal of our research is to improve the thermal performance of the architectural envelope of this type of habitat and thus reduce energy consumption through passive solutions.

\section{The climatic characteristics of the wilaya of BISKRA}

The city of Biskra is located in the South-east of Algeria at a latitude of $34.80^{\circ}$ North and longitude of $5.73^{\circ}$ East (Figure. 3). Biskra belongs to a region classified arid, where a hot and dry climate with cold winters and hot summers predominates. The maximum temperature reaches $42 \mathrm{C}^{\circ}$ during the month of July and the minimum temperature decreases to $7 \mathrm{C}^{\circ}$ in winter during the month of January. The average annual temperature is $21.7 \mathrm{C}^{\circ}$, while the average annual humidity is $46 \%$. Very low precipitation is recorded with a maximum of $20 \mathrm{~mm} /$ year, and an annual average of about $8.8 \mathrm{~mm} /$ year. The directions of prevailing wind is North-west in winter, South-east in summer at a speed from 6 to $10 \mathrm{~m} / \mathrm{s}$ (Figure.4).
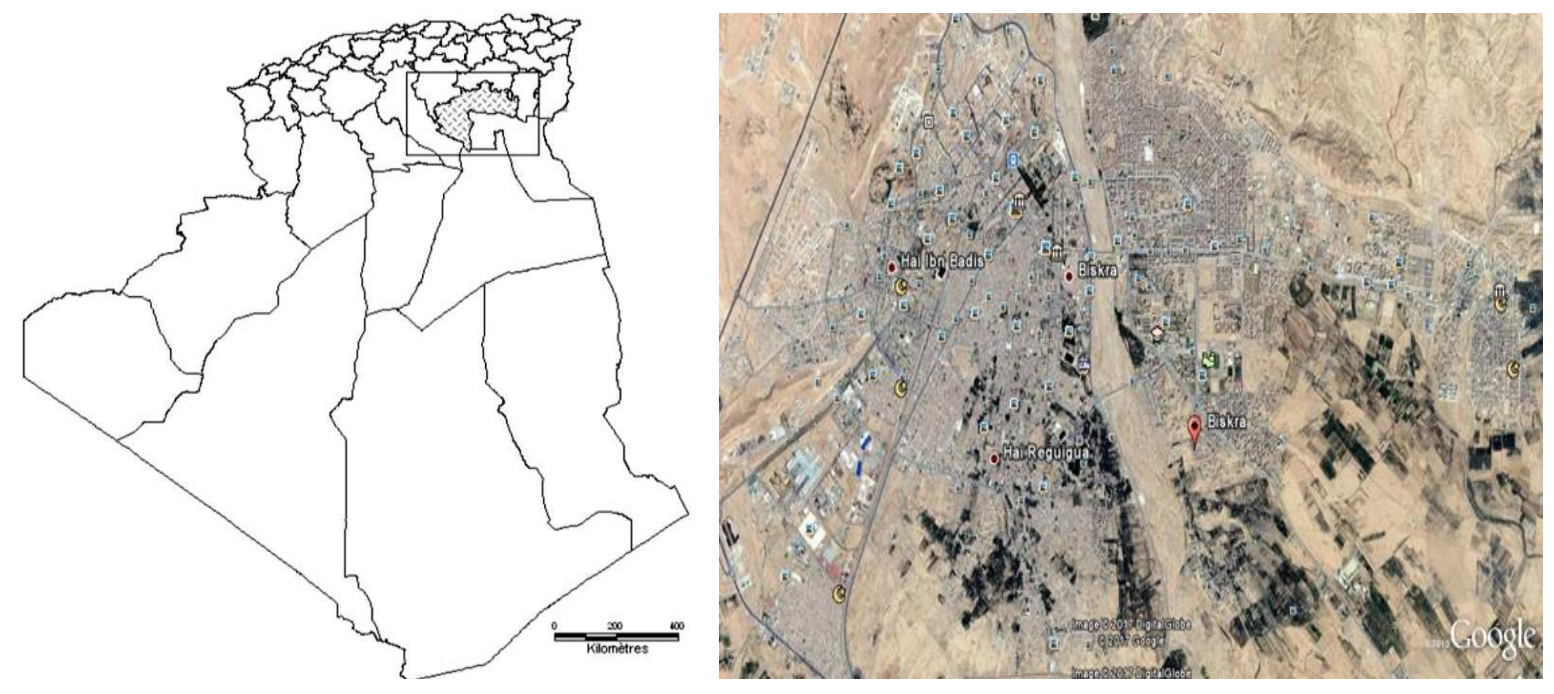

Fig 3: Situation of the Wilaya of Biskra (Source: google earth) 

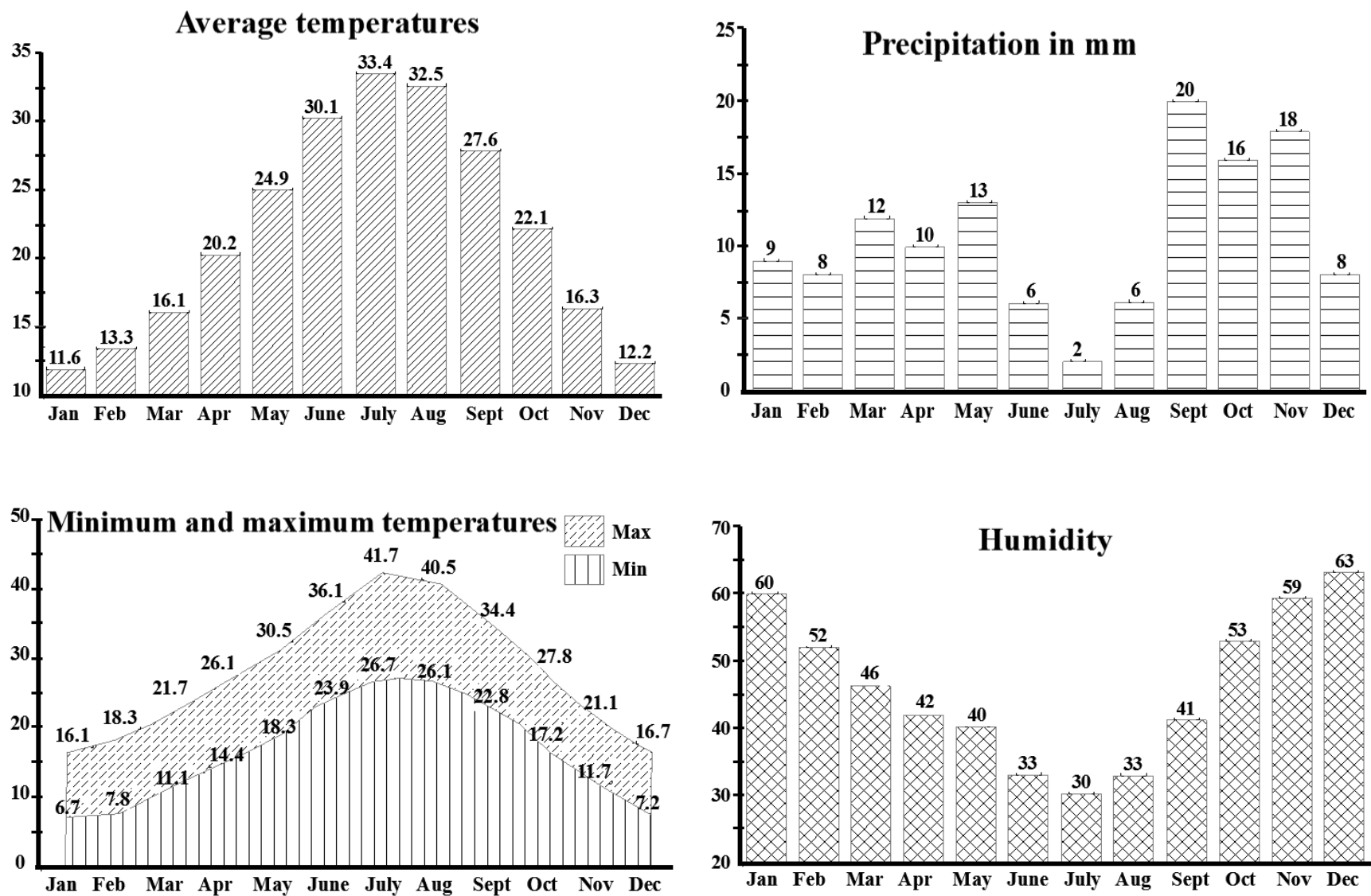

Fig 4: Climatic data of the city of Biskra (Source: Weather station data Biskra, 2000-2009)

According to Givoni (1978), to assure the hygrothermal comfort under a dry hot climate, the buildings must be adapted to the summer conditions and it assuming that a building where the comfort is assured in summer will satisfy the winter requirements. In this study, it will be limited to the presentation of the results obtained during the summer period.

\section{The building envelope and thermal comfort}

From ancient times up to the present day, the man did not stop improving his housing environment to assure a protection always more effective against weather conditions and aggressive factors of the external environment. However, thermal comfort in a building depends mainly on the thermal behaviour of its envelope (Fig. 5) More precisely are the building materials and the architectural and constructive characteristics of the structural elements (wall thickness, compositions, layout ... etc.), which determine the climatic adaptability of a construction.

The outside envelope of the building is its first barrier of protection; it consists of two types of walls: opaque walls (walls and roof) and transparent walls (Windows). The roof is responsible for $70.62 \%$ of the gains received while $27.11 \%$ of the thermal gains are transmitted by the four facades, and $2.27 \%$ by the windows (Necib, 2016). A judicious treatment of the walls of the envelope according to the warm and arid climatic conditions (choice of construction materials with high thermal inertia for walls and roofing, reduction of the dimensions of windows, solar protections ... etc.) allows to guarantee an optimal comfort inside the building, even if the outside conditions are unfavorable (Izard, 1979). 


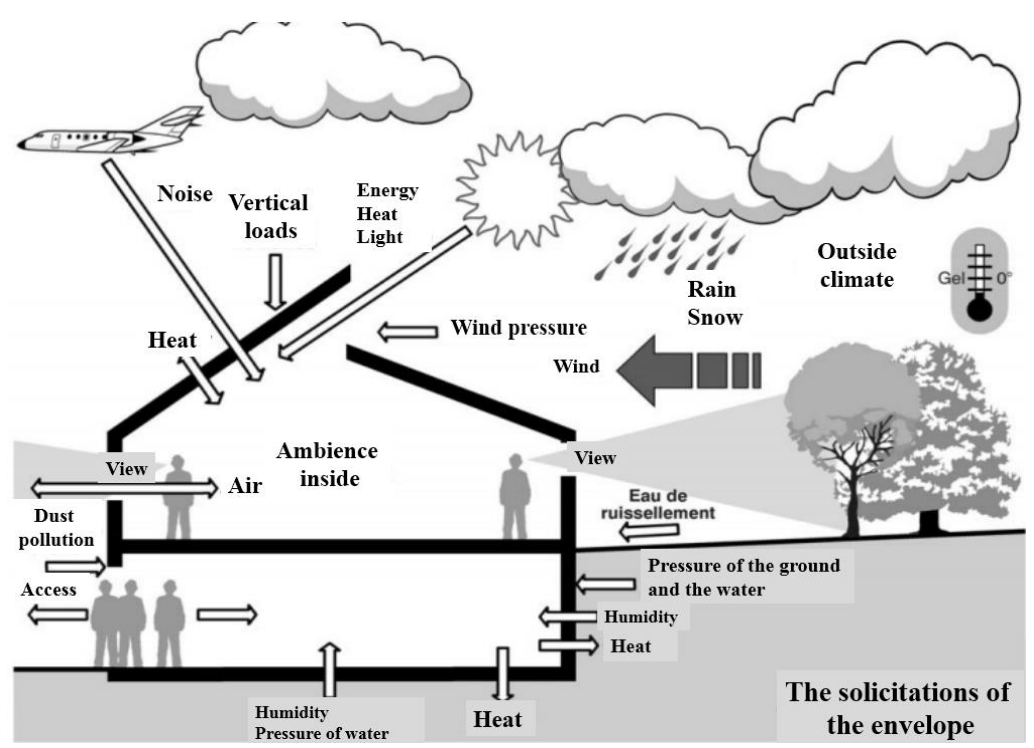

Fig. 5: The outside envelope undergoes numerous aggressions of the local climate and the environment (source: Hauglustaine, 2006)

\section{Experimental study}

Our analytical work based on a survey in situ intended for the study of the structural and constructive parameters of the envelope influence on the thermal comfort. This one is measured from the ambient and surface temperature, the air speed, and the relative humidity. The measuring instrument TESTO was used to raise the variations of the previous three hygrothermal parameters while the surface temperature was measured with an infrared thermometer (figure. 6). The measures were made inside, outside of the room, and in various points, in particular the roof and the wall of facade (Figure.7).

To select houses to be studied, it was necessary to perform a typo-morphological analysis. An important corpus of contemporary individual self-produced in Biskra was assembled. The houses were distributed in different planned subdivisions of the city and their choice was made according to the characteristics of the most recurring envelope (orientation, building materials, ratio of openings, number of levels ... etc.). In total, 15 variants of rooms were studied.

The analysis of the climatic data of Biskra allowed us to determine the period of overheating, which is approximately one week from the end of July to the beginning of August. The recording of the measurements took place at two times of the day from $14 \mathrm{pm}$ to $16 \mathrm{pm}$ in the afternoon and from 9 am to $11 \mathrm{am}$ in the morning.
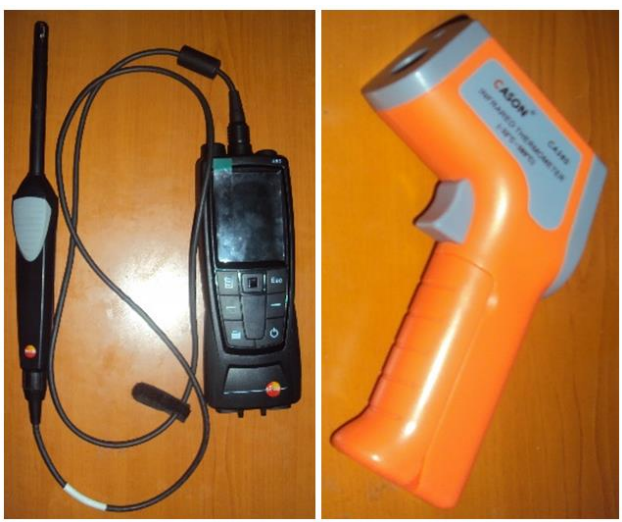

Fig. 6 : Measuring instrument TESTO and infrared thermometer

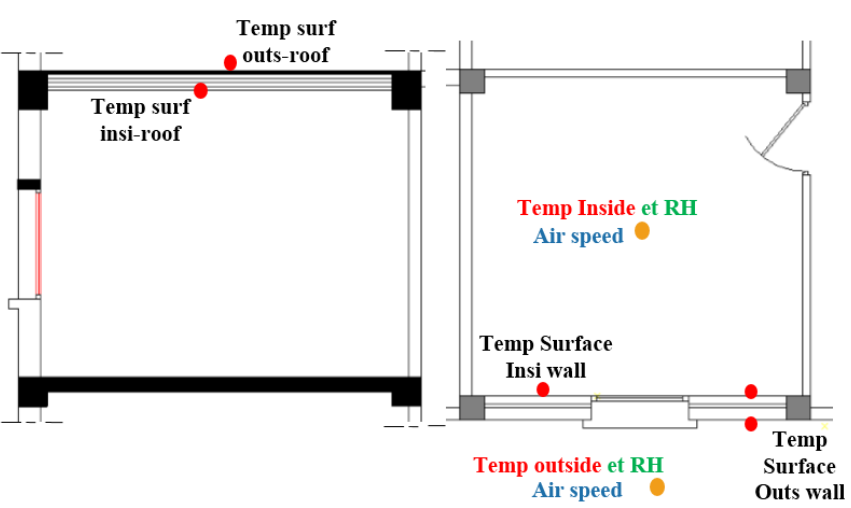

Fig. 7: Position of measurement points in the room 
In order to study the impact of the building materials used at the envelope level, several cases have been chosen. The sample includes 15 variants that illustrate the different constructive systems of exterior walls used in the Biskra (Table 1). In addition to the walls, two other parameters have been taken into account: the orientation and position of the room in the house is in the ground floor (unexposed roof, floor), or on the upper level (exposed roof, terrace).

Table 1: Distribution of the 15 variants of the studied pieces

\begin{tabular}{|c|c|c|c|c|}
\hline \multicolumn{3}{|c|}{ Table 1: Distribution of the 15 variants of the studied pieces } \\
\hline $\begin{array}{c}\text { Walls in hollow } \\
\text { perpend ( } 2 \\
\text { variants) }\end{array}$ & $\begin{array}{c}\text { Walls in full } \\
\text { perpend ( 1 } \\
\text { variant) }\end{array}$ & $\begin{array}{c}\text { Walls simple brick- } \\
\text { built of 15cm (4 } \\
\text { variants in the } \\
\text { floor) }\end{array}$ & $\begin{array}{c}\text { Walls brick-built double } \\
\text { of 15cm X2 (2var. RDC, } \\
\text { 3var. R+1) }\end{array}$ & $\begin{array}{c}\text { Walls brick with blade } \\
\text { of air (1var double. } \\
\text { RDC, 2var. R+1) }\end{array}$ \\
\hline
\end{tabular}

To illustrate the obtained results at the end of the campaign of measure, it was chosen to present some examples showing the parameters of thermal comfort (temperature, relative humidity, air velocity) measured in parts that differ according to Three parameters: the physical and constructive characteristics of the walls, the orientation and the type of roofing (floor or terrace) (Table 2).

Table 2: Examples of results of the measures made in situ in rooms using various building materials for walls;

\begin{tabular}{|c|c|c|c|c|c|c|}
\hline $\begin{array}{l}\text { Wall in hollow brick } \\
(17 \mathrm{~cm}) \text {, located on } \\
\text { the floor, orientation } \\
\text { South }\end{array}$ & & \multicolumn{3}{|c|}{$\begin{array}{c}+ \text { chambre } \\
12 \mathrm{~m}^{2}\end{array}$} & 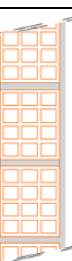 & \\
\hline \multicolumn{7}{|c|}{ Ambient temperature $\mathrm{C}^{\circ}$} \\
\hline & \multicolumn{3}{|c|}{ Morning } & \multicolumn{3}{|c|}{ Afternoon } \\
\hline & Max & Min & Moy & $\operatorname{Max}$ & Min & Moy \\
\hline Temp inside & 35.2 & 34.6 & 34.8 & 39 & 36.8 & 38 \\
\hline Temp outside & 39.1 & 33.1 & 37.8 & 44 & 40 & 41.5 \\
\hline Thermal gap & 4 & 1.5 & 3 & 5 & 3.2 & 3.5 \\
\hline \multicolumn{7}{|c|}{ Surface temperature $\mathrm{C}^{\circ}$} \\
\hline Temp surf insi wall & 36.4 & I & 36.4 & 38.5 & 1 & 37.6 \\
\hline Temp surf outs wall & 40.6 & 1 & 40.1 & 46.9 & 1 & 45.6 \\
\hline Thermal gap & 4.2 & I & 3.7 & 8.4 & 1 & 8 \\
\hline Temp surf insi roof & 36.8 & l & 36.6 & 37.5 & I & 37.5 \\
\hline Temp surf outs wall & 42.6 & I & 42 & 41.6 & 1 & 41.2 \\
\hline Thermal gap & 5.8 & 1 & 5.4 & 4.1 & 1 & 3.7 \\
\hline \multicolumn{7}{|c|}{ Relative Humidity $\%$} \\
\hline Humidity indoor & 26.4 & 24.8 & 25.6 & 26.3 & 22.5 & 24.2 \\
\hline Humidity outside & 20.3 & 19.7 & 20 & 14 & 13 & 13.3 \\
\hline
\end{tabular}

\begin{tabular}{|c|c|c|c|c|c|c|}
\hline \multirow{3}{*}{\begin{tabular}{|l|} 
Walls brick with \\
blade of air $33 \mathrm{~cm}$ \\
located on the floor, \\
orientation west
\end{tabular}} & \multirow{3}{*}{\multicolumn{3}{|c|}{ 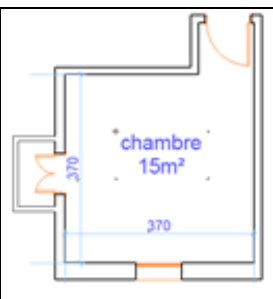 }} & \multirow{3}{*}{\multicolumn{2}{|c|}{ 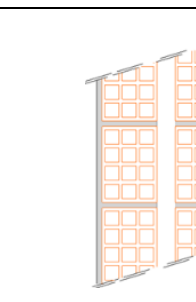 }} & \multirow{3}{*}{$\pi$} \\
\hline & & & & & & \\
\hline & & & & & & \\
\hline \multicolumn{7}{|c|}{ Ambient temperature $\mathrm{C}^{\circ}$} \\
\hline & \multicolumn{3}{|c|}{ Morning } & \multicolumn{3}{|c|}{ Afternoon } \\
\hline & Max & Min & Moy & Max & Min & Moy \\
\hline Temp inside & 41.3 & 33.3 & 32.5 & 36.6 & 34 & 36.3 \\
\hline Temp outside & 37.3 & 37.2 & 37 & 42.3 & 41 & 41.8 \\
\hline Thermal gap & 4 & 3.9 & 4.5 & 5.7 & 5 & 5.5 \\
\hline \multicolumn{7}{|c|}{ Surface temperature $\mathrm{C}^{\circ}$} \\
\hline Temp surf insi wall & 37.7 & 1 & 37.6 & 38.5 & 1 & 38.1 \\
\hline Temp surf outs wall & 41.6 & 1 & 41.4 & 49 & 1 & 48.4 \\
\hline Thermal gap & 4 & 1 & 3.8 & 10.5 & 1 & 10.3 \\
\hline Temp surf insi roof & 38.4 & 1 & 38.1 & 39.6 & 1 & 39.3 \\
\hline Temp surf outs wall & 34.4 & 1 & 34.4 & 46.8 & 1 & 46.4 \\
\hline Thermal gap & 4 & I & 3.7 & 7.2 & 1 & 7.1 \\
\hline \multicolumn{7}{|c|}{ Relative Humidity \% } \\
\hline Humidity indoor & 25.9 & 24.7 & 25.4 & 20.6 & 20 & 20.3 \\
\hline Humidity outside & 21.8 & 20.6 & 21.2 & 13.9 & 13 & 13.3 \\
\hline
\end{tabular}




\begin{tabular}{|c|c|c|c|c|c|c|}
\hline \multicolumn{1}{|c|}{ Air speed $\mathrm{m} / \mathrm{s}$} \\
\hline Air Speed inside & 0,3 & 0 & 0,1 & 0,3 & 0 & 0,1 \\
\hline Air Speed outside & 1,3 & 0,3 & 0.6 & 1,9 & 0,5 & 1.2 \\
\hline
\end{tabular}

\begin{tabular}{|c|c|c|c|c|c|c|}
\hline $\begin{array}{l}\text { Wall in hollow brick } \\
15+15(32 \mathrm{~cm}) \text {, } \\
\text { located on the floor, } \\
\text { orientation North- } \\
\text { west }\end{array}$ & & IIt & in & $\begin{array}{l}+ \\
25 m^{2} \\
\\
\text { f }\end{array}$ & & \\
\hline \multicolumn{7}{|c|}{ Ambient temperature $\mathrm{C}^{\circ}$} \\
\hline & \multicolumn{3}{|c|}{ Morning } & \multicolumn{3}{|c|}{ Afternoon } \\
\hline & Max & Min & Moy & Max & Min & Moy \\
\hline Temp inside & 35,3 & 35,3 & 35,3 & 38 & 37,6 & 37,8 \\
\hline Temp outside & 39,6 & 38 & 39,2 & 42,8 & 34,3 & 42,6 \\
\hline Thermal gap & 4.3 & 2.7 & 4 & 4.8 & 3.3 & 4.8 \\
\hline \multicolumn{7}{|c|}{ Surface temperature $\mathrm{C}^{\circ}$} \\
\hline Temp surf insi wall & 35 & I & 34.1 & 38,5 & I & 38 \\
\hline Temp surf outs wall & 38.3 & 1 & 36.5 & 45,5 & 1 & 44,7 \\
\hline Thermal gap & 3.3 & 1 & 2.4 & 7 & 1 & 6.7 \\
\hline Temp surf insi roof & 38,4 & 1 & 38,4 & 38,8 & 1 & 38,7 \\
\hline Temp surf outs wall & 35,8 & 1 & 34,7 & 47,5 & 1 & 47,1 \\
\hline Thermal gap & 2.6 & 1 & 3.7 & 8.7 & 1 & 8.4 \\
\hline \multicolumn{7}{|c|}{ Relative Humidity $\%$} \\
\hline Humidity indoor & 30,7 & 26,7 & 29 & 26,7 & 20 & 21,8 \\
\hline Humidity outside & 23,2 & 20,4 & 21,6 & 15,4 & 14,8 & 15,5 \\
\hline \multicolumn{7}{|c|}{ Air speed m/s } \\
\hline Air Speed inside & 0,3 & 0 & 0,1 & 0,3 & 0 & 0 \\
\hline Air Speed outside & 1,9 & 0,3 & 0,7 & 0,5 & & 0,3 \\
\hline
\end{tabular}

\begin{tabular}{|c|c|c|c|c|c|c|}
\hline \multicolumn{7}{|c|}{ Air speed $\mathrm{m} / \mathrm{s}$} \\
\hline Air Speed inside & 0.5 & 0 & 0.2 & 0.3 & 0 & 0.1 \\
\hline Air Speed outside & 1 & 0.3 & 0.5 & 1.9 & 0.5 & 1.2 \\
\hline
\end{tabular}

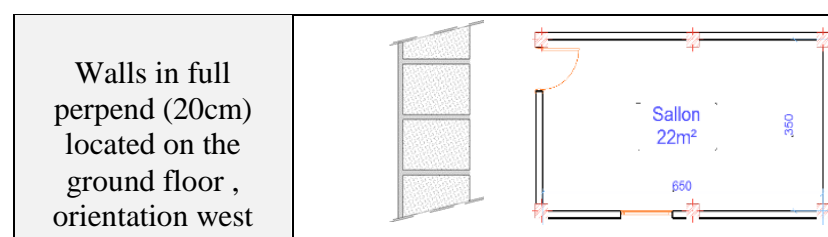

orientation west

\begin{tabular}{|c|c|c|c|c|c|c|c|}
\hline \multicolumn{8}{|c|}{ Ambient temperature C $\mathrm{C}^{\circ}$} \\
\hline & \multicolumn{3}{|c|}{ Morning } & \multicolumn{3}{c|}{ Afternoon } \\
\cline { 2 - 8 } & Max & Min & Moy & Max & Min & Moy \\
\hline Temp inside & 37,4 & 37 & 37,1 & 40,3 & 40,1 & 40,2 \\
\hline Temp outside & 40 & 39 & 39,7 & 41.5 & 40,8 & 41 \\
\hline Thermal gap & 2.6 & 2 & 2.6 & 1.2 & 0.7 & 0.8 \\
\hline \multicolumn{8}{|c|}{ Surface temperature C ${ }^{\circ}$} \\
\hline
\end{tabular}

\begin{tabular}{|l|c|c|c|c|c|c|}
\hline \multicolumn{1}{|c|}{ Surface temperature C } \\
\hline Temp surf insi wall & 36,4 & $/$ & 37,1 & 42,1 & $/$ & 41,7 \\
\hline Temp surf outs wall & 41,2 & $/$ & 41 & 45,4 & $/$ & 45 \\
\hline Thermal gap & 4.8 & $/$ & 3.9 & 3.3 & $/$ & 3.3 \\
\hline Temp surf insi roof & 37,1 & $/$ & 37 & 44,7 & $/$ & 44,3 \\
\hline Temp surf outs wall & 39,2 & $/$ & 38,6 & 50,6 & $/$ & 49 \\
\hline Thermal gap & 2.1 & $/$ & 1.6 & 5.9 & $/$ & 4.7 \\
\hline \multicolumn{7}{|c|}{ Relative Humidity \% } \\
\hline Humidity indoor & 31,1 & 24,2 & 26,1 & 21,4 & 19 & 19,6 \\
\hline Humidity outside & 21,8 & 21,6 & 21,7 & 19,4 & 17,5 & 18,2 \\
\hline \multicolumn{7}{|c|}{ Air speed $\mathrm{m} / \mathrm{s}$} \\
\hline Air Speed inside & 0 & 0 & 0 & 0 & 0 & 0 \\
\hline Air Speed outside & 1,4 & 0,4 & 0,8 & 0,5 & 0 & 0,3 \\
\hline
\end{tabular}

\begin{tabular}{|c|c|c|c|c|c|c|}
\hline $\begin{array}{l}\text { Walls in hollow } \\
\text { perpend }(22 \mathrm{~cm}) \\
\text { located on the ground } \\
\text { floor south-west } \\
\text { orientation }\end{array}$ & & & & 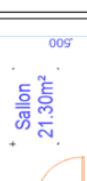 & $\approx$ & \\
\hline \multicolumn{7}{|c|}{ Ambient temperature $\mathrm{C}^{\circ}$} \\
\hline & \multicolumn{3}{|c|}{ Morning } & \multicolumn{3}{|c|}{ Afternoon } \\
\hline & Max & Min & Moy & Max & Min & Moy \\
\hline Temp inside & 32,2 & 32 & 32,1 & 37,7 & 34,7 & 36,5 \\
\hline Temp outside & 34,8 & 34 & 34.3 & 41,1 & 38,4 & 37.5 \\
\hline Thermal gap & 2.6 & 2 & 2.2 & 3.4 & 0.5 & 1 \\
\hline \multicolumn{7}{|c|}{ Surface temperature $\mathrm{C}^{\circ}$} \\
\hline Temp surf insi wall & 31,5 & 1 & 31,2 & 37,2 & I & 36.9 \\
\hline Temp surf outs wall & 35,8 & 1 & 35,4 & 45,7 & I & 45 \\
\hline Thermal gap & 4.3 & 1 & 4.2 & 8.5 & 1 & 8.1 \\
\hline \multicolumn{7}{|c|}{ Relative Humidity $\%$} \\
\hline Humidity indoor & 39,4 & 34,8 & 35,6 & 32,1 & 26,2 & 29,4 \\
\hline Humidity outside & 32,8 & 31,3 & 31,8 & 21,5 & 17,9 & 20 \\
\hline \multicolumn{7}{|c|}{ Air speed $\mathrm{m} / \mathrm{s}$} \\
\hline Air Speed inside & 0.5 & 0 & 0,1 & 0,6 & 0,0 & 0,1 \\
\hline Air Speed outside & 2.1 & 0.3 & 1 & 2,6 & 0,3 & 1 \\
\hline
\end{tabular}




\section{Interpretation of the results}

\subsection{Air temperature}

According to Bennadji (1999), the subtraction of the external average temperatures from those of the interior of the room allows to appreciate the temperature difference between the inside and the outside. In table 2 , it is noted that there is a difference of $0.5 \mathrm{C}^{\circ}$ to $2 \mathrm{C}^{\circ}$ between these two temperatures in a house built in single wall (single partition). The maximum value of ambient temperature is recorded in houses built in hollow and full block; for these cases, the indoor temperature is in the order of $32^{\circ}$ to $38^{\circ}$ at the time when the outside temperature reaches the $40^{\circ}$. This constructive choice is visibly inadequate for the warm and arid climate. For the rooms built on the floor the situation of discomfort is at its extreme, for example for a piece built in single $15 \mathrm{~cm}$ brick wall, the average temperature difference is in the order of $3 \mathrm{C}^{\circ}$ to $3.5 \mathrm{C}^{\circ}$.

On the other hand, in the houses built in double partition, the temperature difference is more appreciable. As an example, for double brick walls of $15 \mathrm{~cm}$, it is between $4 \mathrm{C}^{\circ}$ to $4.5 \mathrm{C}{ }^{\circ}$ (the internal temperature reaches $23.5 \mathrm{C}^{\circ}$, outside it is $26.5 \mathrm{C}^{\circ}$ ). In the case of double walled walls with a blade of air, the thermal gap between the inside and outside is optimal in the order of $5 \mathrm{C}$ to $5.5 \mathrm{C}^{\circ}$.

In conclusion, it appears that the highest indoor temperatures are recorded in simple walled rooms with low thermal resistance materials such as hollow and full block. On the other hand, the walls in double walls give more interesting results from the point of view of thermal comfort in the summer period. Note that the ambient temperatures measured are also dependent on other factors such as orientation and external climatic fluctuations.

\subsection{The relative humidity and the air speed}

When reading the results of the measurements, we can be said that the external relative humidity is low compared to the internal humidity, on the outside it usually varies between $15 \%$ and $19 \%$ and inside it is between $22 \%$ and $31 \%$. These results can be explained by human metabolism vapor and domestic activities and also the lack of aeration in the house.

According to Liebard (2005), the air velocity that does not exceed $0.2 \mathrm{~m} / \mathrm{s}$ in the habitat has an influence on convective heat exchanges. However, with respect to the parts tested, the air velocity was very low not exceeding $0.1 \mathrm{~m} / \mathrm{s}$ due to the lack of transverse ventilation.

\subsection{The values of the surface temperature}

According to Szokolay (2004), the temperature of the external surface has great effects on the internal thermal conditions; moreover, it varies with the clarity of the color and the velocity of the air in contact with the surface. Based on the results obtained, it appears that the temperatures of the internal surfaces are higher than the ambient temperature when the walls are exposed to solar radiation. Thus, the higher the external surface temperature increases due to the lack of shading and the lack of solar protections at the level of openings, the higher the ambient temperature rises in proportion to the external surface temperature. The temperature of the air and the surface temperature are therefore linked both by the amount of the incident solar radiation and also by the thermo-physical properties of the building materials, which retard the transfer of the heat inside. 


\section{Conclusions}

Through an experimental in situ study of a single-detached houses corpus in Biskra, the influence of the structural and constructive choices of the architectural envelope on the inner thermal comfort was examined. This experiment has shown that a judicious choice of materials can positively influence the inner thermal comfort, especially thanks to the thermo-physical properties of the materials that allow regulating heat exchanges between the building and its environment. The double-walled walls offer some advantages from the point of view of thermal comfort during the summer period. Moreover, the thermal operation of the enclosure can be optimized thanks to the integration of the solar protections according to the orientation of the façade.

\section{References}

APRUE, (2015). Final energy consumption of Algeria, key figure-year 2015; Ministry of Energy and Mines.

Bennadji, A. (1999). Climatic or cultural Adaptation in arid zones: case of the Algerian South-East. PhD thesis. Université d'Aix-Marseille1-Université de Provence.

Hauglustaine J.-M. (2006). The Global Conception of the envelope and the energy, a practical Guide for architects; Ministry of the Walloon Region; February 2006.

Givoni, B. (1978). Man architecture and climate. Editions Le Moniteur, Paris, France, 460 p.

Izard, J. L. (1979). Archi Bio; Editions parentheses; Roquevaire, 1979.

Liebard, A. (2005). Treatise on Bioclimatic Architecture and urbanism: design, build and develop with sustainable development. Editions Le Moniteur, Paris, France, 2005.

Necib, H (2016). Improved thermal insulation of habitats in warm and arid regions. Third International Conference on Energy, materials, Applied Energetic And Pollution. ICEMAEP 2016; Constantine, Algeria

Szokolay, V. (2004). Introduction to architectural science, the basis of sustainable design. Architectural Press Edition, edition An imprint of Elsevier Science, 348p. 